\title{
Using gait score, walking speed, and lying behavior to detect hoof lesions in dairy cows
}

\author{
N. Chapinal, ${ }^{* 1}$ A. M. de Passillé, † D. M. Weary, ${ }^{*}$ M. A. G. von Keyserlingk, ${ }^{*}$ and J. Rushen† \\ *Animal Welfare Program, University of British Columbia, 2357 Main Mall, Vancouver, British Columbia, V6T 1Z4, Canada \\ †Agriculture and Agri-Food Canada, PO Box 1000, Agassiz, British Columbia, V0M 1A0, Canada
}

\begin{abstract}
The objective was to determine whether changes in the different components of gait, walking speed, and lying behavior were associated with hoof pathologies in lactating Holstein cows. In experiment 1, 53 cows had their gait scored, their walking speed estimated, and their lying behavior monitored before clinical assessment of the hooves. Multiparous cows with ulcers scored higher than cows without ulcers for overall gait score [numerical rating score (NRS); $3.3 \pm 0.2$ vs. 2.8 $\pm 0.2]$, back arch, joint flexion, asymmetric steps, and reluctance to bear weight. Although cows with ulcers did not walk more slowly than cows without ulcers (1.4 $\mathrm{m} / \mathrm{s})$, they spent more time lying down $(827.8 \pm 29.1$ vs. $738.2 \pm 15.5 \mathrm{~min} / \mathrm{d}$ ) because of longer lying bouts $(93.3 \pm 5.9$ vs. $79.7 \pm 3.4 \mathrm{~min})$. In experiment 2,47 cows were monitored for hoof health and changes in gait score from 4 wk before to 24 wk after calving. Differences were found after calving between cows that developed an ulcer and cows that did not for NRS (3.1 \pm 0.1 vs. $2.35 \pm 0.1$ ), back arch, joint flexion, asymmetric steps, and reluctance to bear weight. Numerical rating score, back arch, and asymmetric steps were able to discriminate cows with ulcers at least $4 \mathrm{wk}$ before the diagnosis. Cows that developed a sole ulcer had a faster decline in lying time during the periparturient period and a faster increase beginning in wk 2 after calving. The NRS was a more consistent predictor of sole ulcers than lying behavior or speed. The NRS was able to discriminate cows with ulcers across studies at a high intraobserver accuracy and reasonable specificity and was able to predict the presence of ulcers at least 4 wk before diagnosis. Abduction/adduction of the rear legs, head bob, and tracking-up did not consistently discriminate cows with ulcers, and we suggest that these measures are less useful for on farm gait assessment. Compared with the other gait attributes, back
\end{abstract}

Received February 9, 2009.

Accepted May 8, 2009.

${ }^{1}$ Corresponding author: nchapinal@yahoo.com arch, joint flexion, asymmetric steps, and reluctance to bear weight best predicted the presence of sole ulcers.

Key words: gait score, lameness, sole ulcer, lying behavior

\section{INTRODUCTION}

Dairy producers typically underestimate the incidence of lameness in their herds (Whay et al., 2003), which shows the need for better detection methods. Although automated detection methods show potential for identifying lame cows (Rushen et al., 2007), gait or locomotion scoring likely remains the most practical method for detecting lameness on-farm (Nordlund et al., 2004; Bicalho et al., 2007).

Some gait scoring methods rely on only one or a few specific changes in gait, such as an arched back (Sprecher et al., 1997), likely making these methods easier to use by producers (Cramer, 2007) but potentially compromising reliability and validity. Flower and Weary (2006) proposed a more detailed scoring system based on a range of gait attributes (e.g., head bob, back arch, step asymmetry, and reluctance to bear weight), and this system was validated using a range of approaches. For example, cows had lower scores when walking on rubber than on concrete flooring (Flower et al., 2007) and lower scores when provided local anesthetics or analgesic drugs than when left untreated (Rushen et al., 2007; Flower et al., 2008). Perhaps most relevant for validating gait scoring are differences in gait between cows with and without hoof pathologies. Sole ulcers are one of the most common causes of lameness in dairy cattle (e.g., Manske et al., 2002b; Bicalho et al., 2007), and cows with sole ulcers scored higher than cows without sole lesions (Flower and Weary, 2006; Flower et al., 2007). Unfortunately, the use of multiple components makes this type of scoring system more challenging for use on-farm, and it is not clear which of these gait components are most important. Other measures of behavior such as walking speed (Flower et al., 2006) or changes in lying time (Hassall et al., 1993; Singh et al., 1993; Walker et al., 2008) might provide useful indicators of lameness and hoof pathology. 
The objective was to determine whether changes in the different components of gait, walking speed, and lying behavior were associated with hoof pathologies in lactating Holstein cows. In experiment 1 we assessed the association between the different components of gait, time spent lying, walking speed, and the presence of hoof lesions. In experiment 2, we examined the onset of behavioral changes in relation to the appearance of sole hemorrhages and sole ulcers after calving.

\section{MATERIALS AND METHODS}

\section{General Housing, Procedures, and Measures}

Animals and Housing. Lactating Holstein cows were housed in sand-bedded freestalls $(2.4 \mathrm{~m}$ long $\times$ $1.18 \mathrm{~m}$ wide $\times 0.40 \mathrm{~m}$ deep, at least 1 per cow) at the University of British Columbia's Dairy Education and Research Centre (Agassiz, Canada). This facility had 250 lactating cows, with a mean $( \pm \mathrm{SD}) 305$-d milk production of $11,167 \pm 2,024 \mathrm{~kg}$. Cows were fed a TMR diet twice daily at 0700 and $0400 \mathrm{~h}$ that was formulated to meet requirements for lactating dairy cows (NRC, 2001). Water was freely available from self-filling troughs. Lactating cows were milked twice daily in the parlor at approximately 0800 and $1700 \mathrm{~h}$.

Gait Score. Cows' gaits were scored while they were walking down a $13-\mathrm{m}$ long by $1.3-\mathrm{m}$ wide nongrooved concrete passageway immediately after the morning milking. To encourage cows to walk in a consistent manner, a handler walked immediately behind the cows encouraging them when necessary. Cows were habituated to the procedure by repeatedly walking them down the passageway for at least $4 \mathrm{~d}$ (4 passages/d) before gait scoring. Each cow was videotaped during each of the 4 passages/d at normal speed from her right side with a color digital camera (Sony DCRSR100 HDD Handycam Camcorder, Sony Corp., Park Ridge, NJ; 30 frames $/ \mathrm{s}$ ) placed $8 \mathrm{~m}$ from the cow to allow recording of at least 4 complete strides during each passage. A second video camera (Panasonic CCTV WV-BP310, Matsushita Electric, Mississauga, Ontario, Canada), connected to a time-lapse videocassette recorder ( $\mathrm{Pa}-$ nasonic Time-Lapse VCR, AG-6740, at normal speed in 2 -h mode, 25 frames $/ \mathrm{s}$ ), was mounted $2.7 \mathrm{~m}$ above the floor and pointed toward the rear of the cow, which enabled us to score the abduction/adduction of the rear legs. An experienced observer watched the videos and evaluated 7 specific gait attributes (abduction/adduction of the rear legs, back arch, head bob, tracking-up, joint flexion, asymmetric gait, and reluctance to bear weight) using a 100-unit continuous scale, as described in Flower and Weary (2006; Table 1). A score of 0 represented a sound gait attribute and 100 represented the most extreme example possible. Individual overall gait score was assessed by using a 1 to 5 numerical rating system (NRS; where $1=$ perfect gait and $5=$ severely lame) based on the 7 specific gait attributes (Flower and Weary, 2006; Table 1). If a cow exceeded the requirements of a particular score, a half-integer score was allocated.

Clinical Examination of the Hooves. At each observation, the soles of the hooves were pared minimally by a trained hoof trimmer to expose a clean surface. An experienced observer examined the front and hind hooves of the cows and recorded the presence, location, and severity of sole hemorrhages, sole ulcers, and digital dermatitis. Hemorrhages and ulcers were scored on a 1 to 8 scale as described by Leach et al. $(1998 ; 1=$ diffuse red or yellow; $2=$ stronger red; $3=$ deep, dense red; $4=$ port coloration; $5=$ red, raw; $6=$ ulcer, corium exposed; $7=$ severe ulcer, major loss of horn; 8 = infected ulcer). Digital dermatitis was scored on a 1 to 5 scale as described by Manske et al. (2002a; $1=$ reddened area with erect pili; $2=$ moist, discharge, reddened area with intact epidermis; $3=$ exudative area, exposed corium, no signs of healing; $4=$ exposed corium, but in process of healing, dried up lesion; $5=$ dark brown scab, completely/almost completely healed lesion).

Lying Behavior. A modified data logger (Tinytag Plus, Gemini Dataloggers Ltd., Chichester, UK) was used to quantify the number of lying/standing bouts and their duration and the total time spent lying and standing per day, as described by O'Driscoll et al. (2008). The activity logger was placed in a fabric pouch and attached to either hind leg of each cow using Vet-Wrap (CoFolex, Andover Coated Products Inc., Salisbury, MA). The activity loggers were programmed to record position of the cow (lying or standing) once per minute.

\section{Specific Experimental Procedures}

Experiment 1. The association was assessed between aspects of the gait, lying time, walking speed, and the presence of hoof lesions. Eighty-one lactating cows (parity $=2.6 \pm 0.8$, range: 1 to $9 ; \mathrm{BW}=676 \pm 82$ $\mathrm{kg} ; \mathrm{DIM}=183 \pm 64 \mathrm{~d}$; daily milk production $=38.3 \pm$ $7.7 \mathrm{~kg}$ ) were randomly selected from the herd and fitted with activity loggers $5 \mathrm{~d}$ before clinical examination of the hooves. Because few primiparous cows had sole lesions (only 1 and 3 primiparous cows had sole ulcers and hemorrhages, respectively) and consistently had lower NRS than multiparous cows, even in the absence of hoof lesions as described previously (Chapinal et al., 2009), the analyses between gait attributes, walking speed, activity, and hoof lesions were done using only multiparous cows $(\mathrm{n}=53)$. 
Table 1. Numerical rating system (NRS) for walking dairy cows, adapted from Flower and Weary $(2006)^{1}$

\begin{tabular}{|c|c|c|}
\hline Score (NRS) & Description & Behavioral criteria \\
\hline 3.0 & $\begin{array}{l}\text { Capable of locomotion but ability } \\
\text { to move freely is compromised }\end{array}$ & $\begin{array}{l}\text { Abduction/adduction of the hind legs } \\
\text { Arched back } \\
\text { Steady head carriage } \\
\text { Hind-hooves do not track up } \\
\text { Joints show signs of stiffness but do not impede freedom of movement } \\
\text { Asymmetrical gait } \\
\text { Slight limp can be discerned }\end{array}$ \\
\hline 4.0 & $\begin{array}{l}\text { Ability to move freely is } \\
\text { obviously diminished }\end{array}$ & $\begin{array}{l}\text { Abduction/adduction of the hind legs } \\
\text { Obvious arched back } \\
\text { Head bobs slightly } \\
\text { Hind-hooves do not track up } \\
\text { Strides are hesitant and deliberate and joints are stiff } \\
\text { Asymmetrical gait } \\
\text { Reluctant to bear weight on at least one limb } \\
\text { but still uses that limb in locomotion }\end{array}$ \\
\hline 5.0 & $\begin{array}{l}\text { Ability to move is severely } \\
\text { restricted and animal must be } \\
\text { vigorously encouraged to move }\end{array}$ & $\begin{array}{l}\text { Abduction/adduction of the hind legs } \\
\text { Extremely arched back } \\
\text { Obvious head bob } \\
\text { Poor tracking up with short strides } \\
\text { Obvious joint stiffness characterized by lack of joint } \\
\text { flexion with very hesitant and deliberate strides } \\
\text { Asymmetrical gait } \\
\text { Inability to bear weight on one or more limbs }\end{array}$ \\
\hline
\end{tabular}

${ }^{1}$ If a cow exceeded the requirements of a particular score, a half-integer score was allocated.

Cows were gait scored $4 \mathrm{~d}$ and $1 \mathrm{~d}$ before each clinical examination of the hooves. Walking speed was assessed at the same time gait was scored. Two marks, separated by $9.35 \mathrm{~m}$, were painted on the floor and walls of the passageway. Using the video recordings described above, walking speed was calculated using Observer software (version 5, Noldus Information Technology, Wageningen, the Netherlands) as the time to pass between the 2 markers.

Experiment 2. Changes in gait or lying time were examined in relation to the development of hoof lesions. Thirty-five multiparous cows and 12 primiparous cows were assigned to continuous housing in a free-stall barn or housing on pasture from 2000 to $0700 \mathrm{~h}$ and in a free-stall barn for the rest of the day, from $4 \mathrm{wk}$ before to 8 wk after calving (at which time they were continuously housed in the free-stall barn). Cows had been on pasture for 1 mo (since the time of dry off). All cows in the herd that were $4 \mathrm{wk}$ from calving were eligible for the experiment, but cows that had ulcers or severe hemorrhages before the start of the experiment or scored NRS $>3$ were dismissed. The objective was to assess the effect of overnight pasture on lameness and health. The experimental treatments had no effect on the occurrence of hoof lesions or on gait and the data from the 2 treatments were combined.

Cows were scored for gait and hoof traits every 4 wk until 24 wk after calving by the same experienced observer. Cows were continuously monitored for lying behavior from wk 3 before to wk 5 after calving.

Five multiparous cows and 1 primiparous cow (parity $=3.5 \pm 1.4 ; \mathrm{BW}=620 \pm 92 \mathrm{~kg}$; daily milk production $=43.1 \pm 4.7 \mathrm{~kg}$ ) were diagnosed with a sole ulcer during the postpartum phase of the experiment. The multiparous cows had ulcers in the hind lateral digits, whereas the primiparous cow had an ulcer in the hind medial digit. Cows with ulcers were matched with 6 cows that had severe hemorrhages in at least 1 of the hooves (parity $=3.0 \pm 2.1 ; \mathrm{BW}=622 \pm 74 \mathrm{~kg}$; daily milk production $=44.3 \pm 5.4 \mathrm{~kg}$ ) and 6 cows that did 
not have any visible sole lesion (parity $=2.2 \pm 0.8$; BW $=562 \pm 31 \mathrm{~kg}$; daily milk production $=37.7 \pm 5.7 \mathrm{~kg}$ ), matching for parity (primiparous/multiparous), experimental treatment, and week of lesion diagnosis.

\section{Statistical Analysis}

All statistical analyses were performed using SAS software (version 9.1; SAS Institute, 2003) using the cow as the experimental unit. Numerical rating score, gait attributes, speed, and activity variables were treated as dependent interval variables in all analyses. Residuals were always examined to verify normality and homogeneity of variances. The NRS was an ordinal variable, but because it included 9 different response categories and assumptions of normality and homogeneity of variances were met, it was treated as an interval dependent variable in all analyses (Chuang-Stein and Agresti, 1997).

In experiment 1, NRS, gait attributes, and speed values from each cow (1 passage per day per cow) were averaged to provide 1 value per cow. The lying behavior data from 4 consecutive days were averaged to provide 1 value per cow for the frequency of lying bouts, lying time, and mean duration of the standing and lying bouts over a 24 -h period. Activity data were lost for 1 cow.

Cows were classified as having a particular hoof lesion if at least 1 digit was affected. In a preliminary analysis, digital dermatitis did not affect $(P>0.20)$ NRS, gait attributes, speed, or activity. Therefore, foot lesions were categorized into 4 mutually exclusive hoof health categories for the analysis: 1) cows with no lesions $(\mathrm{n}=9) ; 2)$ cows with only digital dermatitis $(\mathrm{n}=$ 7); 3) cows with moderate or severe hemorrhages (lesion score 3 to 5 ; they could have digital dermatitis, $\mathrm{n}=$ 24 ); and 4) cows with sole ulcers (lesion score $\geq 6$; they could also have hemorrhages and digital dermatitis, $n$ $=13$ ). Cows with other kinds of lesions (e.g., interdigital hyperplasia) but not having sole hemorrhages, sole ulcers, or digital dermatitis were not included in the analysis $(\mathrm{n}=3)$.

To test the effect of hoof health category on all the dependent variables (NRS, gait attributes, speed, and activity measures), contrast statements were used within the GLM procedure to test cows with no lesions against each of the other hoof health categories, and cows with ulcers against all the other categories together.

The gait attributes were analyzed using discriminant analysis to determine which combination of variables could most accurately discriminate cows with ulcers (PROC STEPDISC) and the accuracy of each attribute (PROC DISCRIM). For this analysis, hoof health was dichotomized as with or without sole ulcer. The crite- rion for entering or leaving the model was an $\alpha$ value of 0.05 . Using different clinical thresholds, sensitivity (likelihood that a cow with an ulcer scored equal or higher than the threshold), specificity (likelihood that a cow without an ulcer scored lower than the threshold), and accuracy (likelihood that a cow was correctly classified by the threshold) were calculated for NRS. Pearson correlation was used (PROC CORR) to describe how gait attributes were related to each other and to speed and activity.

In experiment 2, changes in NRS and the 7 gait attributes from wk 4 before to wk 24 after calving were compared between cows that did not develop any lesions and cows that developed severe hemorrhages (lesion score $=5$ ) or ulcers (lesion score $\geq 6$ ). Because no differences were detected at wk 4 before calving across hoof health categories (PROC GLM), gait scores (NRS and gait attributes) corresponding to that week were included as a covariate in an analysis of covariance (PROC MIXED). The final model included the initial gait scores as a covariate, hoof health category as a factor, week as a continuous repeated measure, and all the pairwise interactions. Cow was considered a random effect and compound symmetry was specified as the covariance structure. Contrast statements were used to compare cows with no lesions versus those with hemorrhages and those with ulcers separately and cows with ulcers against the 2 other categories. Three of the gait attributes (head bob, tracking-up, and reluctance to bear weight) did not meet the normality and homoscedasticity assumptions because of a high frequency of cows scoring zero, especially at wk 4 before calving. Therefore, an average across the postpartum period was calculated for tracking-up and reluctance to bear weight, and differences were tested by using Wilcoxon rank-sum test. Only 3 cows presented head bob over the experiment (1 belonging to each hoof health category), so this variable was dropped from the analysis. In a second analysis, behaviors were analyzed in relation to the time when lesions were first diagnosed. Specifically, changes in NRS, abduction/adduction, back arch, joint flexion, and asymmetric steps were analyzed by 4 -wk period, from $8 \mathrm{wk}$ before to $4 \mathrm{wk}$ after the lesions were diagnosed using PROC GLM. Because reluctance to bear weight was highly correlated to joint flexion and asymmetric steps, this variable was not included in this analysis.

Lying behavior data were averaged by week. Analysis was performed using a mixed model (PROC MIXED) with hoof health category, week, the quadratic effect of week, and the interaction between them as fixed effects, cow as a random effect, week as a continuous repeated measure, and compound symmetry as the covariance structure. 
Table 2. Percentage of cows in experiment 1 that were diagnosed at least once with each type of lesion and the percentage of cows suffering from each type of lesion that also had other types of lesions $(n=81)$

\begin{tabular}{|c|c|c|c|c|c|c|}
\hline Type of lesion & \multicolumn{6}{|c|}{ Percentage } \\
\hline Cows with ulcer & $17(14)$ & NA & 7 & 71 & 36 & 7 \\
\hline Cows with dermatitis $^{3}$ & $22(18)$ & 6 & NA & 39 & 28 & 50 \\
\hline Cows with hemorrhages ${ }^{4}$ & $47(38)$ & 26 & 18 & NA & 10 & 56 \\
\hline
\end{tabular}

${ }^{1}$ Total number of cows in parentheses.

${ }^{2} \mathrm{NA}=$ not applicable.

${ }^{3}$ Digital dermatitis.

${ }^{4}$ Only cows with moderate or severe hemorrhages were included.

\section{RESULTS}

\section{Experiment 1}

Hoof Lesions. Table 2 shows the percentage of cows that had at least 1 instance of each type of lesion and the co-occurrence of different types of lesions. Sole hemorrhages were most frequently diagnosed, either on their own or in combination with sole ulcers, digital dermatitis, or both. Only moderate and severe cases of hemorrhages were accounted for in Table 2. Eleven cows had ulcers on the hind hooves and 3 had ulcers on their front hooves. Nine medial digits and 12 lateral digits had an ulcer (4 cows had more than 1 ulcer in different digits). Four cows had digital dermatitis on the front hooves and 15 on the hind hooves ( 2 cows had digital dermatitis in both front and back). All cases of digital dermatitis were in an early stage of the disease and there were no cases with major exposure of the corium. Most of the cows with hoof lesions were multiparous: $62 \%$ of the primiparous cows and $17 \%$ of the multiparous cows had no hoof lesions.

Gait Scores. Numerical rating score was correlated with head bob, tracking-up, joint flexion, asymmetric steps, and reluctance to bear weight, and these gait attributes correlated with one another (Table 3).
Parity affected gait score independently of hoof health. When multiparous and primiparous cows with no lesions were compared, multiparous cows had higher NRS $(2.9 \pm 0.1$ vs. $2.0 \pm 0.1 ; P<0.001)$. No primiparous cow had an NRS greater than 3 . Four had an NRS of 3: 1 with no sole lesion, 1 with digital dermatitis only, 1 with hemorrhage, and 1 with sole ulcer. Among multiparous cows, there were no differences between cows with no lesions, cows with digital dermatitis only, or cows with hemorrhages for NRS or any of the specific gait attributes (Table 4). When cows with ulcers were tested against all the other hoof health categories, they scored higher than cows without ulcers for NRS and all the gait attributes except for abduction/adduction and tracking-up, with only a tendency for head bob.

The initial discriminant analysis showed that back arch $\left(\mathrm{R}^{2}=0.09, P=0.03\right)$, head bob $\left(\mathrm{R}^{2}=0.08, P=\right.$ $0.04)$, joint flexion $\left(\mathrm{R}^{2}=0.11, P=0.02\right)$, asymmetric steps $\left(\mathrm{R}^{2}=0.13, P=0.01\right)$, and reluctance to bear weight $\left(\mathrm{R}^{2}=0.12, P=0.01\right)$ discriminated cows with ulcers from those without ulcers. However, the final stepwise model only included reluctance to bear weight as a predictor of sole ulcers $\left(\mathrm{R}^{2}=0.11, P=0.02\right)$.

Table 5 shows the specificity, sensitivity, and accuracy of the NRS and of each gait component in discriminat-

Table 3. Pearson correlations among numerical rating system (NRS) and different gait attributes for multiparous cows $(\mathrm{n}=53)$ in experiment 1

\begin{tabular}{|c|c|c|c|c|c|c|c|}
\hline Gait attribute & NRS & $\begin{array}{l}\text { Abduction/ } \\
\text { adduction }\end{array}$ & Back arch & Head bob & Tracking up & Joint flexion & Asymmetric steps \\
\hline Abduction/adduction & $0.32 *$ & - & & & & & \\
\hline Back arch & $0.41^{* *}$ & 0.22 & - & - & - & - & - \\
\hline Head bob & $0.73^{* * *}$ & 0.17 & $0.42^{* *}$ & - & - & - & - \\
\hline Tracking up & $0.68^{* * *}$ & 0.27 & $0.27^{*}$ & $0.61^{* * *}$ & - & - & - \\
\hline Joint flexion & $0.77^{* * *}$ & $0.35^{*}$ & $0.32^{*}$ & $0.66^{* * *}$ & $0.62 * * *$ & - & - \\
\hline Asymmetric steps & $0.91^{* * *}$ & 0.24 & $0.33^{*}$ & $0.71^{* * *}$ & $0.72^{* * *}$ & $0.81^{* * *}$ & - \\
\hline Reluctance to bear weight & $0.90^{* * *}$ & $0.31^{*}$ & $0.35^{*}$ & $0.74^{* * *}$ & $0.71^{* * *}$ & $0.81^{* * *}$ & $0.93^{* * *}$ \\
\hline
\end{tabular}

*** $P<0.001 ;{ }^{* *} P<0.01 ;{ }^{*} P<0.05$. 
Table 4. Least squares means $( \pm \mathrm{SE})$ for numerical rating system (NRS), walking speed, and score on each gait attribute for multiparous cows in experiment 1 with no lesions $(\mathrm{n}=9)$, with digital dermatitis only $(\mathrm{n}=$ $7)$, with sole hemorrhages $(\mathrm{n}=24)$, and with sole ulcers $(\mathrm{n}=13)^{1}$

\begin{tabular}{|c|c|c|c|c|}
\hline \multirow[b]{2}{*}{ Variable } & \multicolumn{4}{|c|}{ Hoof health category } \\
\hline & No lesions & Dermatitis & Hemorrhages & Ulcer \\
\hline $\mathrm{NRS}^{2}$ & $2.9 \pm 0.2$ & $3.0 \pm 0.2$ & $2.7 \pm 0.2$ & $3.3 \pm 0.2^{*}$ \\
\hline Speed $(\mathrm{m} / \mathrm{s})$ & $1.4 \pm 0.07$ & $1.4 \pm 0.08$ & $1.4 \pm 0.04$ & $1.4 \pm 0.06$ \\
\hline Abduction/adduction ${ }^{3}$ & $21.1 \pm 6.9$ & $28.7 \pm 7.8$ & $20.3 \pm 4.2$ & $21.4 \pm 6.2$ \\
\hline Back $\operatorname{arch}^{3}$ & $18.1 \pm 4.9$ & $26.8 \pm 5.5$ & $24.6 \pm 3.0$ & $34.1 \pm 4.1^{*}$ \\
\hline Head bob ${ }^{3}$ & $10.3 \pm 5.1$ & $9.6 \pm 5.8$ & $5.5 \pm 3.1$ & $17.2 \pm 4.2 \dagger$ \\
\hline Tracking $u^{3}$ & $17.7 \pm 6.5$ & $16.5 \pm 7.4$ & $17.5 \pm 4.0$ & $26.1 \pm 5.4$ \\
\hline Joint flexion ${ }^{3}$ & $31.6 \pm 3.8$ & $35.2 \pm 4.3$ & $29.8 \pm 2.3$ & $40.1 \pm 3.2^{*}$ \\
\hline Asymmetric steps $^{3}$ & $29.8 \pm 4.5$ & $28.7 \pm 5.1$ & $25.2 \pm 2.8$ & $38.7 \pm 3.8^{*}$ \\
\hline Reluctance to bear weight ${ }^{3}$ & $18.5 \pm 5.1$ & $15.0 \pm 5.7$ & $11.3 \pm 3.1$ & $26.4 \pm 4.2^{*}$ \\
\hline
\end{tabular}

ing multiparous cows with sole ulcers. Numerical rating score with a threshold of 3.5 had similar specificity, sensitivity, and accuracy to the specific gait attributes back arch, joint flexion, asymmetric steps, and reluctance to bear weight.

Walking Speed and Lying Behavior. Walking speed did not differ across hoof health categories (Table 4). In general, walking speed was negatively correlated (Table 6) with NRS and all other gait attributes. The highest correlation was with tracking-up.

Cows with sole hemorrhages and cows with digital dermatitis did not differ from animals with no lesions in total time spent lying down, frequency of lying bouts, or duration of the lying bout (Table 7). When cows with ulcers were tested against all the other hoof health categories, they had a higher daily lying time. This difference was caused by an increased duration of lying bouts. Total daily lying time was correlated with NRS and with 5 of the gait attributes, excluding abduction/ adduction of the rear legs and back arch (Table 6).

\section{Experiment 2}

Four weeks before calving, no differences in NRS or any specific gait attribute were found between cows with no lesions and cows that later developed hemorrhages or ulcers (Table 8). We noted no differences between cows without sole lesions and cows that developed a sole hemorrhage over the $24 \mathrm{wk}$ after calving. Yet, cows that developed sole ulcers scored higher than cows that did not develop sole ulcers for NRS (Figure 1), back arch, joint flexion, asymmetric gait, and reluctance to bear weight over the same period (Table 8). Most cows, regardless of hoof health, scored zero for tracking-up

Table 5. Specificity, sensitivity, and accuracy of the numerical rating system (NRS) and each component of the gait in differentiating cows with ulcers $(n=13)$ from cows without ulcers $(n=40)$ in experiment $1^{1}$

\begin{tabular}{lcccc}
\hline Variable & Threshold & Specificity (\%) & Sensitivity (\%) & Accuracy (\%) \\
\hline NRS $^{2}$ & 3 & 38 & 85 & 49 \\
& 3.5 & 70 & 54 & 66 \\
Abduction/adduction $^{3,4}$ & 4 & 95 & 38 & 81 \\
Back arch $^{3}$ & 14 & 45 & 55 & 47 \\
Head bob $^{3}$ & 28 & 68 & 46 & 62 \\
Tracking up $^{3,4}$ & 12 & 62 & 71 & 55 \\
Joint flexion $^{3}$ & 23 & 60 & 54 & 66 \\
Asymmetric steps $^{3}$ & 35 & 70 & 54 & 70 \\
Reluctance to bear weight $^{3}$ & 36 & 75 & 54 & \\
${ }^{1}$ Clinical thresholds were set for NRS. The thresholds for the components of the gait were calculated from the \\
discriminant analysis. \\
${ }^{2}$ Scored on a 5-point scale with half-integer scores. \\
${ }^{3}$ Variables were scored on continuous 100-unit visual analog scales. \\
${ }^{4} P>0.05$ in the initial discriminant analysis.
\end{tabular}


Table 6. Pearson correlations between scores on each gait attribute and walking speed $(\mathrm{n}=53)$ and standing time $(\mathrm{n}=52)$ for multiparous cows in experiment 1

\begin{tabular}{llc}
\hline Gait attribute & Speed & Lying time \\
\hline Numerical rating system $^{1}$ & $-0.34^{*}$ & $0.41^{* *}$ \\
Abduction/adduction $^{2}$ & $-0.29^{*}$ & 0.12 \\
Back arch $^{2}$ & $-0.34^{*}$ & 0.19 \\
Head bob $^{2}$ & $-0.32^{*}$ & $0.40^{* *}$ \\
Tracking up $^{2}$ & $-0.51^{* * *}$ & $0.29^{*}$ \\
Joint flexion $^{2}$ & $-0.46^{* * *}$ & $0.44^{* *}$ \\
Asymmetric steps $^{2}$ & $-0.36^{* *}$ & $0.40^{* * *}$ \\
Reluctance to bear weight $^{2}$ & $-0.33^{*}$ & $0.56^{* * *}$ \\
${ }^{1}$ Scored on a 5-point scale with half-integer scores. & \\
${ }^{2}$ Variables were scored on continuous 100-unit visual analog scales. & \\
${ }^{* * *} P<0.001 ; * * P<0.01 ;{ }^{*} P<0.05$. &
\end{tabular}

and reluctance to bear weight 4 wk before calving. Therefore, no analysis was performed for that week.

When data were reanalyzed relative to the time that the lesion was diagnosed (Figure 2), NRS and back arch consistently discriminated cows with ulcers from $4 \mathrm{wk}$ before to 4 wk after diagnosis. Asymmetric steps could discriminate cows $4 \mathrm{wk}$ before and in the week that cows were diagnosed. There was a tendency $(P=0.06)$ for NRS to discriminate cows that developed ulcers 8 wk before diagnosis. No differences between cows with severe sole hemorrhage and cows without sole lesions were found for any measure.

When lying time was analyzed, a hoof health category by week interaction $(P=0.002)$ and a hoof health category by quadratic week interaction $(P=0.02)$ were found (Figure 3). Subsequent analyses were stratified by hoof health category. The daily lying time followed a linear pattern in the case of cows with no lesions $(P$ $<0.001$ ), but followed a quadratic pattern in the case of cows with ulcers $(P<0.001)$. In other words, cows that developed sole ulcers had a faster decrease in lying time during the periparturient period, and a faster increase beginning in wk 2 after calving. We noted no effect of hoof health or time on the frequency of daily lying bouts. During the 3 -wk period before calving, the number of daily bouts was $10.7 \pm 0.7,10.6 \pm 0.7$, and $9.3 \pm 0.7$ for cows with no lesions, hemorrhage, and ulcer, respectively, whereas during the 5 -wk period after calving, the frequency of daily bouts was $11.1 \pm$ $1.2,8.9 \pm 1.2$, and $9.7 \pm 1.2$, for cows with no lesions, hemorrhage, and ulcer, respectively.

\section{DISCUSSION}

In both experiments, we found that sole ulcers are closely associated with higher gait scores, supporting studies using this scoring method and other approaches (Whay et al., 1997; Manske et al., 2002b; Flower and Weary, 2006). Cows with sole ulcers showed higher NRS than cows without ulcers, whereas no differences were found between cows with no lesions and those with mild digital dermatitis and sole hemorrhages (Manske et al., 2002b; Flower and Weary, 2006; Flower et al., 2007). Changes in NRS predicted ulcer development, but not hemorrhage, as we were able to identify afflicted cows at least $4 \mathrm{wk}$ before the ulcer was visible on the sole. The NRS remained high for at least 4 wk after the ulcer diagnosis.

To identify lame cows, a threshold must be agreed upon. Flower and Weary (2006) treated NRS as a continuum and used discriminant analysis (rather than using different clinical thresholds) to show that

Table 7. Least squares means $( \pm \mathrm{SE})$ for lying time, bout frequency, and lying bout duration for multiparous cows in experiment 1 with no lesions $(\mathrm{n}=9)$, with digital dermatitis only $(\mathrm{n}=7)$, with sole hemorrhages $(\mathrm{n}$ $=23)$, and with sole ulcer $(\mathrm{n}=13)^{1}$

\begin{tabular}{lcccc}
\hline & \multicolumn{4}{c}{ Hoof health category } \\
\cline { 2 - 5 } Variable & No lesions & Dermatitis & Hemorrhages & Ulcer \\
\hline Lying time (min/d) & $756.3 \pm 34.9$ & $717.95 \pm 39.6$ & $737.0 \pm 21.8$ & $827.8 \pm 29.1^{*}$ \\
Bout frequency (no./d) & $10.9 \pm 0.7$ & $9.6 \pm 0.7$ & $9.4 \pm 0.4$ & $9.2 \pm 0.5$ \\
Lying bout duration (min) & $71.0 \pm 7.1$ & $81.1 \pm 8.1$ & $82.7 \pm 4.5$ & $93.3 \pm 5.9^{*}$ \\
\hline${ }^{1}$ All the categories were mutually exclusive. Cows with sole hemorrhages could have digital dermatitis, and \\
cows with ulcers could have hemorrhages, and there was one cow with both ulcer and digital dermatitis. \\
${ }^{*} P<0.05$ when cows with ulcer were tested against the other hoof conditions.
\end{tabular}




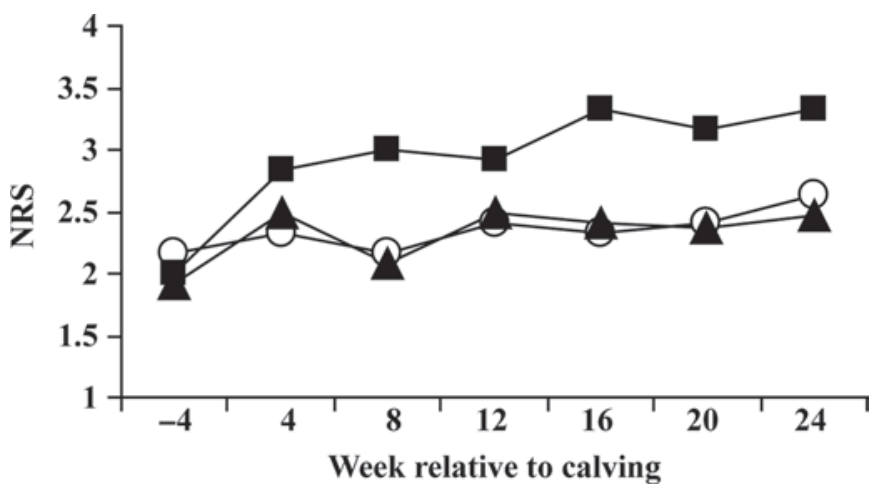

Figure 1. Changes in mean numerical rating system (NRS) for cows with no sole lesions $(\bigcirc)$, with severe sole hemorrhages $(\mathbf{\Lambda})$, and sole ulcers $(\boldsymbol{\square} ; \mathrm{n}=6$ in each category) in experiment 2 . No lesions developed before 8 wk after calving.

NRS $>3$ correctly classified $90 \%$ of the animals with ulcers. Although we did not achieve such high levels of accuracy, we found that a threshold of 3 provided the highest sensitivity, whereas thresholds of 3.5 or 4 provided higher specificity. Bicalho et al. (2007) studied the accuracy of a 1 to 5 scale scoring system in detecting cows with painful lesions, and found that 3 was the best threshold giving a specificity of $85 \%$ and sensitivity of $67 \%$. It should be noted that they did not focus on specific gait attributes and focused on painful foot lesions, including sole ulcers, rather than sole ulcers alone. Ultimately, the optimum threshold will depend on the costs associated with interventions such as hoof trimming relative to the benefits of treating cows with sole ulcers.

The NRS used in this study was based on 7 gait attributes. The system was developed for use in research and benefits from high inter- and intraobserver reliability (Flower and Weary, 2006; Flower et al., 2007;
Borderas et al., 2008). A simplified scoring system based on fewer gait components would be preferable for on-farm use. The 7 gait attributes were independently assessed and cows with ulcers scored higher in back arch, joint flexion, asymmetric steps, and reluctance to bear weight in both experiments. Reasonable levels of intraobserver reliability were previously reported for all 4 gait attributes (Flower et al., 2007; Borderas et al., 2008). Flower and Weary (2006) found that cows with a sole ulcer scored higher in these gait attributes than cows without ulcers. Yet, there is some inconsistency across studies in precisely which gait attributes are able to discriminate cows with and without ulcers. For example, O'Callaghan et al. (2003) found that changes in abduction/adduction were significant, but no other published work to date has replicated this finding.

Assessing gait attributes independently does not tell how well scoring systems based on combinations of these attributes might perform. The results reviewed above suggest that some combination of back arch, joint flexion, asymmetric steps, and reluctance to bear weight might best predict the presence of sole ulcers. Joint flexion, asymmetric steps, and reluctance to bear weight were highly correlated to one another and to NRS (Table 3). Therefore, a simplified scoring system may not require all 3 attributes. Further work is required to assess various simplified gait scoring systems, testing the reliability and validity of these scores by training naïve observers to assess only the selected gait attributes.

Although walking speed was negatively correlated with NRS and gait attributes (Table 6), especially tracking-up, it failed to discriminate cows with mild digital dermatitis, hemorrhages, or ulcers (Table 4). Interestingly, Flower et al. (2005, 2006) and O'Callaghan et al. (2003) reported that cows with ulcers walked

Table 8. Least squares means $( \pm \mathrm{SE})$ for numerical rating system (NRS), abduction/adduction, back arch, joint flexion, and asymmetric steps and means $( \pm \mathrm{SE})$ for tracking-up and reluctance to bear weight 4 wk before calving and during 24 wk after calving (n $=6$ in each health category) in experiment $2^{1}$

\begin{tabular}{|c|c|c|c|c|c|c|}
\hline \multirow[b]{2}{*}{ Gait attribute } & \multicolumn{3}{|c|}{ Before calving } & \multicolumn{3}{|c|}{ After calving } \\
\hline & No lesions & Hemorrhages & Ulcer & No lesions & Hemorrhages & Ulcer \\
\hline $\mathrm{NRS}^{2}$ & $2.2 \pm 0.2$ & $1.9 \pm 0.2$ & $2.0 \pm 0.2$ & $2.3 \pm 0.1$ & $2.4 \pm 0.1$ & $3.1 \pm 0.1^{* *}$ \\
\hline Abduction/adduction ${ }^{3}$ & $32.0 \pm 5.7$ & $12.9 \pm 6.3$ & $19.2 \pm 5.7$ & $28.2 \pm 5.0$ & $17.6 \pm 5.0$ & $22.1 \pm 5.0$ \\
\hline${\text { Back } \operatorname{arch}^{3}}^{3^{\prime}}$ & $15.2 \pm 4.0$ & $12.7 \pm 4.0$ & $17.3 \pm 4.0$ & $24.9 \pm 2.8$ & $27.6 \pm 2.8$ & $45.0 \pm 2.8^{*}$ \\
\hline Joint flexion $^{3}$ & $30.6 \pm 7.5$ & $27.3 \pm 7.5$ & $27.1 \pm 7.5$ & $41.2 \pm 2.9$ & $45.4 \pm 2.9$ & $55.4 \pm 2.9^{* *}$ \\
\hline Asymmetric steps ${ }^{3}$ & $29.2 \pm 8.7$ & $27.5 \pm 8.7$ & $28.8 \pm 8.7$ & $40.3 \pm 2.8$ & $45.2 \pm 2.8$ & $62.2 \pm 2.8^{* * *}$ \\
\hline Tracking up ${ }^{3}$ & $\mathrm{NA}^{4}$ & $\mathrm{NA}$ & NA & $4.1 \pm 2.0$ & $7.5 \pm 2.8$ & $15.6 \pm 8.0$ \\
\hline Reluctance to bear weight $^{3}$ & NA & NA & NA & $1.3 \pm 0.8$ & $0.6 \pm 0.2$ & $11.7 \pm 4.2^{* * 5}$ \\
\hline
\end{tabular}

${ }^{1}$ No lesion developed earlier than 8 wk after calving.

${ }^{2}$ Scored on a 5 -point scale with half-integer scores.

${ }^{3}$ Variables were scored on continuous 100 -unit visual analog scales.

${ }^{4} \mathrm{NA}=$ not applicable; analyses not done as the majority of cows scored zero for these 2 variables.

${ }^{5}$ Difference from cows with no lesions tested with Wilcoxon rank-sum test.

${ }^{* * *} P<0.001 ;{ }^{* *} P<0.01 ;{ }^{*} P<0.05$, when comparing cows with sole ulcer to cows without ulcers. 

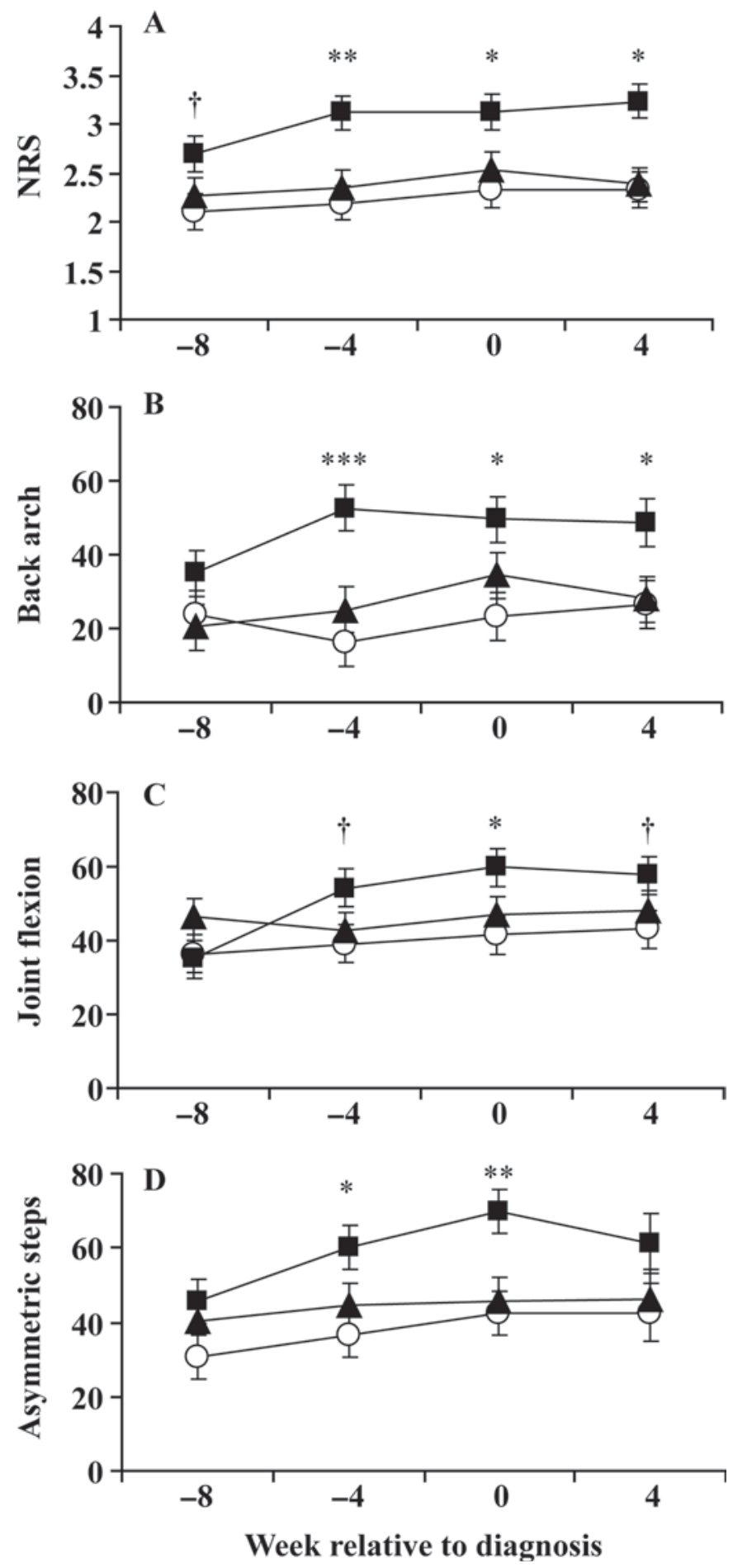

Figure 2. Changes (least squares means $\pm \mathrm{SE}$ ) in numerical rating system (NRS; A), back arch (B), joint flexion (C), and asymmetric steps (D) for cows with no sole lesions $(\bigcirc)$, with severe sole hemorrhages $(\boldsymbol{\Lambda})$, and sole ulcer $(\boldsymbol{\square})(\mathrm{n}=6$ in each category). Wk 0 refers to the week the lesion was diagnosed or the same week relative to calving in the case of the matched cows with no sole lesions. ${ }^{* * *} P<0.001$; ${ }^{* *} P<0.01 ;{ }^{*} P<0.05 ; \dagger P<0.08$ when cows with sole ulcer were tested against the other categories. more slowly than cows without lesions, although Flower et al. (2007) found no differences. It is difficult to determine whether impaired gait results in a slow pace or gait changes are a consequence of slow gait. Flower et al. (2006) suggested that speed interfered with gait scoring, such that cows that walk more slowly are usually given higher scores. Yet, in the current study, cows diagnosed with ulcers scored higher in NRS with no difference in walking speed (Table 4).

Cows with ulcers in experiment 1 had longer lying bouts and consequently, spent more time lying down per day (Table 7). These findings suggest that pain associated with ulcers may reduce the willingness of a cow to stand up once she is lying down. Indeed, NRS and all gait attributes (except for abduction/adduction of the rear legs and back arch) were correlated with daily lying time (Table 6). Previous studies (Hassall et al., 1993; Singh et al., 1993; Walker et al., 2008) reported that overall, lame cows in free-stalls and at pasture lay down for longer than nonlame cows and they attributed this to greater assumed pain and discomfort. Yet, some found reduced daily lying times for lame cows housed in stalls with meager surface cushion (Cook et al., 2004). Environment is known to have an important effect on lying time (Cook and Nordlund, 2009), particularly in the case of lame cows. Clearly, caution is required in extrapolating findings to other housing conditions.

In experiment 2 , we were not able to monitor lying behavior at the time that the ulcers were clinically diagnosed. However, we found that cows that later developed an ulcer had a faster decline in lying time before calving and a faster increase after calving. Standing time was related to the occurrence of sole ulcers, especially around calving (Cook and Nordlund, 2009). Hormonal changes at the time of parturition appear associated with noninflammatory changes in the connective tissue of the corium that impair the resilience of the feet to external stresses (Tarlton et al., 2002; Knott et al., 2007). When cows stand, pressure is placed downward on the third phalanx within the claw horn capsule, thereby compressing the corium beneath the bone and initiating development of claw horn lesions (Lischer et al., 2002). Therefore, cows that stand for longer as calving approaches may be prone to claw horn lesions. These lesions can cause pain and discomfort, leading to reduced mobility and increased lying times.

In conclusion, the gait scoring system based on 7 gait attributes (NRS) appeared a more consistent predictor of sole ulcers compared with the specific gait attributes when assessed independently and compared with time spent lying down or walking speed. A series of studies has now shown that NRS is able to discriminate cows with and without ulcers with high intraobserver reliability and reasonable specificity and sensitivity. 


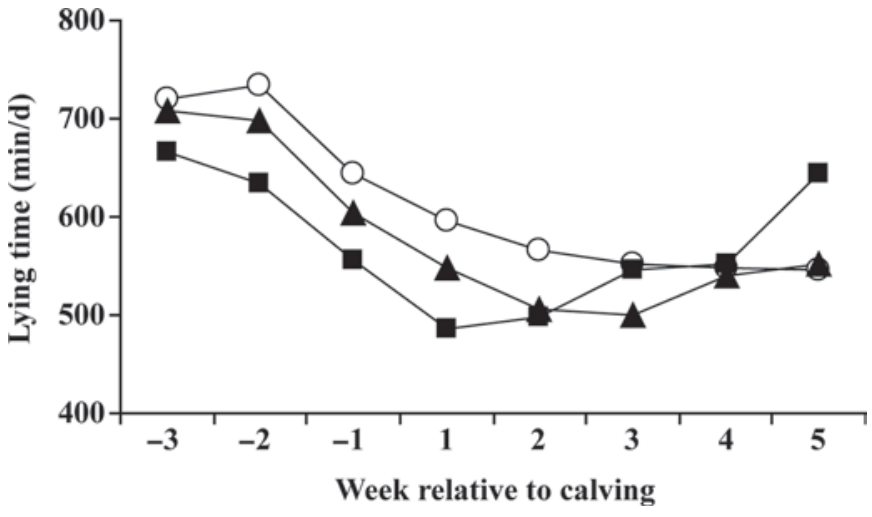

Figure 3. Changes in mean duration of total daily lying time for cows with no sole lesions $(\bigcirc)$, with severe sole hemorrhages $(\mathbf{\Lambda})$, and sole ulcer $(\boldsymbol{\square})(\mathrm{n}=6$ in each category) in experiment 2 .

Furthermore, NRS was able to identify the presence of ulcers at least $4 \mathrm{wk}$ before and up to $4 \mathrm{wk}$ after diagnosis. Abduction/adduction of the rear legs, head bob, and tracking-up did not consistently discriminate cows with ulcers; we suggest that these measures might be dropped from a simplified gait scoring system developed for on-farm use.

\section{ACKNOWLEDGMENTS}

We thank Gosia Zdanowicz, Kate Kjelsrud, Mairi Robertson, Alejandra Barrientos, Christy Goldhawk, and Marianne Villettaz, and the faculty, staff and students at The University of British Columbia's Dairy Education and Research Centre, Agriculture and AgriFood Canada, for their help in running the experiments. The research was supported by the Natural Sciences and Engineering Research Council of Canada (NSERC) and Dairy Farmers of Canada.

\section{REFERENCES}

Bicalho, R. C., S. H. Cheong, G. Cramer, and C. L. Guard. 2007 Association between a visual and an automated locomotion score in lactating Holstein cows. J. Dairy Sci. 90:3294-3300.

Borderas, F., A. Fournier, J. Rushen, and A. M. de Passillé. 2008 Effect of lameness on dairy cow's visits to automatic milking systems (AMS). Can. J. Anim. Sci. 88:1-8.

Chapinal, N., A. M. de Passillé, and J. Rushen. 2009. Weight distribution and gait in dairy cattle are affected by milking and late pregnancy. J. Dairy Sci. 92:581-588.

Chuang-Stein, G., and A. Agresti. 1997. A review of tests for detecting a monotone dose-response relationship with ordinal response data. Stat. Med. 16:2599-2618.

Cook, N. B., T. B. Bennett, and K. V. Nordlund. 2004. Effect of free stall surface on daily activity patterns in dairy cows, with relevance to lameness prevalence. J. Dairy Sci. 87:2912-2922.

Cook, N. B., and K. V. Nordlund. 2009. The influence of the environment on dairy cow behavior, claw health and herd lameness dynamics. Vet. J. 17:360-369.

Cramer, G. 2007. Quantification of foot lesions and an evaluation of early detection methods for lameness in Ontario dairy herds. PhD Thesis. Univ. Guelph, Guelph, Ontario, Canada.
Flower, F. C., A. M. de Passillé, D. M. Weary, D. J. Sanderson, and J. Rushen. 2007. Softer, higher friction flooring improves gait of cows with and without sole ulcers. J. Dairy Sci. 90:1235-1242.

Flower, F. C., D. J. Sanderson, and D. M. Weary. 2005. Hoof pathologies influence kinematic measures of dairy cow gait. J. Dairy Sci. 88:3166-3173.

Flower, F. C., D. J. Sanderson, and D. M. Weary. 2006. Effects of milking on dairy cow gait. J. Dairy Sci. 89:2084-2089.

Flower, F. C., M. Sedlbauer, E. Carter, M. A. von Keyserlingk, D. J. Sanderson, and D. M. Weary. 2008. Analgesics improve the gait of lame dairy cattle. J. Dairy Sci. 91:3010-3014.

Flower, F. C., and D. M. Weary. 2006. Effect of hoof pathologies on subjective assessments of dairy cow gait. J. Dairy Sci. 89:139146.

Hassall, S. A., W. R. Ward, and R. D. Murray. 1993. Effects of lameness on the behaviour of cows during the summer. Vet. Rec. 132:578-580.

Knott, L., J. F. Tarlton, H. Craft, and A. J. Webster. 2007. Effects of housing, parturition and diet change on the biochemistry and biomechanics of the support structures of the hoof of dairy heifers. Vet. J. 174:277-287.

Leach, K. A., D. N. Logue, J. M. Randall, and S. A. Kempson. 1998. Claw lesions in dairy cattle: Methods for assessment of sole and white line lesions. Vet. J. 155:91-102.

Lischer, C. J., U. Koller, H. Geyer, C. Mulling, J. Schulze, and P. Ossent. 2002. Effect of therapeutic dietary biotin on the healing of uncomplicated sole ulcers in dairy cattle: A double blinded controlled study. Vet. J. 163:51-60.

Manske, T., J. Hultgren, and C. Bergsten. 2002a. Topical treatment of digital dermatitis associated with severe heel-horn erosion in a Swedish dairy herd. Prev. Vet. Med. 53:215-231.

Manske, T., J. Hultgren, and C. Bergsten. 2002b. Prevalence and interrelationships of hoof lesions and lameness in Swedish dairy cows. Prev. Vet. Med. 54:247-263.

Nordlund, K. V., N. B. Cook, and G. R. Oetzel. 2004. Investigation strategies for laminitis problem herds. J. Dairy Sci. 87(E Suppl.):E27-E35

NRC. 2001. Nutrient Requirements of Dairy Cattle. 7th rev. ed. National Academy Press, Washington, DC.

O'Callaghan, K. A., P. J. Cripps, D. Y. Downham, and R. D. Murray 2003. Subjective and objective assessment of pain and discomfort due to lameness in dairy cattle. Anim. Welf. 12:605-610.

O'Driscoll, K., L. Boyle, and A. Hanlon. 2008. A brief note on the validation of a system for recording lying behaviour in dairy cows. Appl. Anim. Behav. Sci. 111:195-200.

Rushen, J., E. Pombourcq, and A. M. de Passillé. 2007. Validation of two measures of lameness in dairy cows. Appl. Anim. Behav. Sci. 106:173-177.

SAS Institute. 2003. SAS User's Guide. SAS Institute Inc., Cary, NC

Singh, S. S., W. R. Ward, K. Lautenbach, and R. D. Murray. 1993 Behaviour of lame and normal dairy cows in cubicles and in a straw yard. Vet. Rec. 133:204-208.

Sprecher, D. J., D. E. Hostetler, and J. B. Kaneene. 1997. A lameness scoring system that uses posture and gait to predict dairy cattle reproductive performance. Theriogenology 47:1179-1187.

Tarlton, J. F., D. E. Holah, K. M. Evans, S. Jones, G. R. Pearson, and A. J. Webster. 2002. Biomechanical and histopathological changes in the support structures of bovine hooves around the time of first calving. Vet. J. 163:196-204.

Walker, S. L., R. F. Smith, J. E. Routly, D. N. Jones, M. J. Morris, and H. Dobson. 2008. Lameness, activity time-budgets, and estrus expression in dairy cattle. J. Dairy Sci. 91:4552-4559.

Whay, H. R., D. C. Main, L. E. Green, and A. J. Webster. 2003 Assessment of the welfare of dairy cattle using animal-based measurements: Direct observations and investigation of farm records. Vet. Rec. 153:197-202.

Whay, H. R., A. E. Waterman, and A. J. F. Webster. 1997. Associations between locomotion, claw lesions and nociceptive threshold in dairy heifers during the peri-partum period. Vet. J. 154:155-161. 